\title{
Stage III Colon Cancer AJCC v7
}

National Cancer Institute

\section{Source}

National Cancer Institute. Stage III Colon Cancer A/CC v7. NCI Thesaurus. Code C89995.

Stage III includes: IIIA (T1-T2, N1/N1C, M0); (T1, N2a, M0); IIIB (T3-T4a, N1/N1C, M0); (T2-T3, N2a, M0); (T1-T2, N2b, M0); IIIC (T4a, N2a, M0); (T3-T4a, N2b, M0); (T4b, N1-

N2, M0). T1: Tumor invades submucosa. T2: T umor invades muscularis propria. T3: Tumor invades through the muscularis propria into pericolorectal tissues. T4a: Tumor penetrates to the surface of the visceral peritoneum. T4b: Tumor directly invades or is adherent to other organs or structures. N0: No regional lymph node metastasis. N1: Metastasis in 1-3 regional lymph nodes. N1c: Tumor deposit(s) in the subserosa, mesentery, or nonperitonealized pericolic or perirectal tissues without regional lymph node metastasis. N2: Metastasis in four or more regional lymph nodes. N2a: Metastasis in 4-6 regional lymph nodes. N2b: Metastasis in seven or more regional lymph nodes. M0: No distant metastasis. (AJCC 7th ed.) 